\title{
Stunting at birth: recognition of early-life linear growth failure in the western highlands of Guatemala
}

\author{
Noel W Solomons ${ }^{1}$, Marieke Vossenaar ${ }^{1, *}$, Anne-Marie Chomat $^{2}$, Colleen M Doak ${ }^{3}$, \\ Kristine G Koski ${ }^{2}$ and Marilyn E Scott ${ }^{2}$ \\ ${ }^{1}$ Center for Studies of Sensory Impairment, Aging and Metabolism (CeSSIAM), 17 Avenida \# 16-89 (interior), \\ Zona 11 (Anillo Periferico), Guatemala City 01011, Guatemala: ${ }^{2}$ Institute of Parasitology and School of Dietetics \\ of Human Nutrition, McGill University, Ste Anne de Bellevue, Quebec, Canada: ${ }^{3}$ Department of Health Sciences, \\ Vrije Universeit, Amsterdam, The Netherlands
}

Submitted 7 0ctober 2013: Final revision received 16 September 2014: Accepted 1 October 2014: First published online 27 November 2014

\begin{abstract}
Objective: Measurements of length at birth, or in the neonatal period, are challenging to obtain and often discounted for lack of validity. Hence, classical 'under-5' stunting rates have been derived from surveys on children from 6 to 59 months of age. Guatemala has a high prevalence of stunting (49.8\%), but the age of onset of growth failure is not clearly defined. The objective of the study was to assess length-for-age within the first 1.5 months of life among Guatemalan infants.

Design: As part of a cross-sectional observational study, supine length was measured in young infants. Mothers' height was measured. Length-for-age $Z$-scores (HAZ) were generated and stunting was defined as HAZ $<-2$ using WHO growth standards.

Setting: Eight rural, indigenous Mam-Mayan villages ( $n$ 200, $100 \%$ of Mayan indigenous origin) and an urban clinic of Quetzaltenango ( $n$ 106, $27 \%$ of Mayan indigenous origin), Guatemala.

Subjects: Three hundred and six newborns with a median age of $19 \mathrm{~d}$.

Results: The median rural HAZ was -1.56 and prevalence of stunting was $38 \%$; the respective urban values were -1.41 and $25 \%$. Linear regression revealed no relationship between infant age and $\operatorname{HAZ}\left(r=0 \cdot 101, r^{2}=0 \cdot 010, P=0.077\right)$. Maternal height explained $3 \%$ of the variability in $\mathrm{HAZ}\left(r=0 \cdot 171, r^{2}=0 \cdot 029\right.$, $P=0 \cdot 003)$.

Conclusions: Stunting must be carried over from in utero growth retardation in short-stature Guatemalan mothers. As linear growth failure in this setting begins in utero, its prevention must be linked to maternal care strategies during gestation, or even before. A focus on maternal nutrition and health in an intergenerational dimension is needed to reduce its prevalence.
\end{abstract}

Keywords Linear growth Length-for-age Stunting Young infants Guatemala
Chronic malnutrition or stunting, notably prevalent in Guatemala, is a reduction of linear growth associated with a series of adverse consequences. These include increased mortality, diminished disease resistance and reduced cognitive function in childhood, along with restricted physical capacity in adults and enhanced risk of obstructed labour in childbirth ${ }^{(1,2)}$. The most recent UNICEF State of the World's Children statistics ${ }^{(3)}$ report an aggregate prevalence of stunting among surveyed children, aged 6 to 59 months, of $40 \%$ in the African region, $35 \%$ in the Asia region and $14 \%$ in the Latin Americas region. However, within the Americas, the Central American Republic of Guatemala has the highest rate of stunting, with a $49.8 \%$ prevalence according to the most recent national nutrition survey ${ }^{(3)}$, when measured with respect to the WHO standards ${ }^{(4)}$. The designation of stunting as 'chronic malnutrition' would implicitly suggest a dietary origin, but a diverse series of environmental influences including microbial contamination ${ }^{(5)}$, mycotoxins ${ }^{(6,7)}$, indoor smoke $^{(8)}$, recurrent diarrhoea $^{(9,10)}$, helminth infection ${ }^{(11,12)}$ and environmental enteric dysfunction ${ }^{(13,14)}$ have been postulated to explain more of the variance than can be explained simply by poor nutrient intake ${ }^{(5,15)}$.

On a global basis, UN statistics document a progressive and steep decline in length-for-age status during the first three years of life ${ }^{(16)}$. Since national survey statistics for stunting cover the 6-59 months age group, the linear growth situation for the earliest period of the lifespan, 
back to the time of birth, is shrouded with some uncertainty. This relates to a series of technical and procedural issues. The inability to be present at the moment of birth, technical issues with the measurement procedure and even reluctance to manipulate the newborn into an extended posture are barriers to reporting length data at birth. When available, however, the untrained and non-standardized nature of community field workers performing the measurements leads to scepticism as to the validity of length determinations at birth. Despite the aforementioned issues, there is, of course, an absolute requirement for early measurements of length in certain circumstances, such as in the construction of growth curves; the cross-national procedures to maximize standardization of anthropometric measurements have been published by the WHO Multicentre Growth Reference Study Group ${ }^{(17,18)}$.

A recent sample of 148 term infants in the central highlands of Guatemala was followed with serial anthropometry monitoring over 12 months, initiating from the moment of birth; measurements were obtained by community field workers in the investigative team. The initial mean lengthfor-age $Z$-score (HAZ), measured at an average of 5.6 (SD 2.7) d since birth, was -1.0 (SD 1.0), indicating a certain degree of linear growth retardation at the moment of birth $^{(19)}$. Two field studies in the Quetzaltenango Province of Guatemala, one conducted in eight rural hillside hamlets of Mam-speaking households and another recruiting women attending an urban public health clinic $^{(20,21)}$, serve as a further basis for observations that focus attention on substantial short stature among children measured shortly after birth. The central objective of the present study was to explore the possibility that some degree of retardation in linear growth leading to stunting may have been accumulated even at the moment of birth.

\section{Methods}

\section{Sites and settings}

Both studies were conducted in Quetzaltenango Province in the western highlands of the Republic of Guatemala, with its capital $210 \mathrm{~km}$ from Guatemala City along the Pan American highway being the second most populous city of Guatemala. It is an agricultural zone of both commercial (garden vegetables, coffee, livestock) and subsistence (maize, beans, potato) cultivation. It has a mixed population of Mayan Quiche and Mam indigenous groups living in both rural and urban locations and of non-indigenous (mixed indigenous Mayan and Spanish European) descent, largely concentrated in the urban zones. The study sites ranged from $2333 \mathrm{~m}$ above sea level (urban area) to as high as $3200 \mathrm{~m}$ above sea level in the most elevated of the rural villages.

The rural-village arm of the study took place in June 2012 through May 2013 in eight rural Mam-speaking hamlets in the municipality of the San Juan Ostuncalco, with populations of between 1100 and 3400 inhabitants. Mother-infant dyads were identified and invited to participate by community health workers as part of a larger research study investigating maternal-infant health and determinants of early infant stunting. Only those women who consented to participate were enrolled. Gestational age was not considered for enrolment or analysis.

The urban-clinic arm of the study took place in the city of Quetzaltenango. Mother-infant dyads were identified as they presented to the local public health clinic, when they were invited to participate as part of a larger research study investigating adherence to the WHO recommendations for early feeding practices among low-income residents of the metropolitan area of Quetzaltenango. Inclusion criterion included the recall affirmation that the children were of 'term' births.

\section{Participants}

We enrolled 200 infants (2-45 d old) and their mothers at the rural-village site and 106 infants (4-33 d old) and their mothers at the urban-clinic site. All research was conducted in accordance with prevailing ethical principles. Ethics approval was obtained from McGill University (rural study) and from the Center for Studies of Sensory Impairment, Aging and Metabolism (CeSSIAM; urban and rural studies).

\section{Anthropometric measurements}

The infant's recumbent supine length was measured three times according to standardized procedures using a SECA 2010 infantometer; the average length of three measurements was recorded to the nearest $0.5 \mathrm{~cm}$. Maternal height was measured using a wall stadiometer at each of the eight rural villages and at the urban clinic. Stature was recorded to the nearest $0.5 \mathrm{~cm}$ with the woman standing without shoes and the gaze in the Frankfort plane. Anthropometric measurements were performed in all cases among a total of three members of the CeSSIAM staff based in the Quetzaltenango offices, all trained as nutritionists. Before deployment to the field, the team of staff members undertook a standardization exercise with infants to the point of inter-observer adequacy according to the procedure outlined by Lohman et $a l^{(22)}$. Only one single anthropometrist conducted all measurements at the urban clinic. The remaining two had worked with older infants in the urban-clinic setting before moving to the rural-village project duties, including the measurements within the first month of life.

\section{Data handling and statistical analysis}

HAZ were calculated using the WHO Child Growth Standards ${ }^{(4)}$. Stunting was categorized using WHO definitions. Stunting was defined as $\mathrm{HAZ}<-2 \cdot 0$. Moderate stunting was defined as $\mathrm{HAZ} \geq-3$ and $<-2$. Severe stunting was defined as HAZ $<-3$. 
The statistical software package IBM SPSS Statistics version 21 was used for all statistical analyses. Descriptive statistics were used to describe the population (ethnicity, infant sex distribution), infant stunting prevalence and HAZ (mean, median and standard deviation) in both study settings. Since the HAZ distribution was not normal, differences in median HAZ between sites and infant sex were assessed using the non-parametric Mann-Whitney $U$ test. Differences in stunting prevalence were assessed using the $\chi^{2}$ test. Linear regression analysis was used to test if age of the infant (in days) and maternal height (in centimetres) significantly predicted infant HAZ.

\section{Results}

The mean height of all 306 mothers was 147.9 (SD 5.7) cm (range $133.0-169.0 \mathrm{~cm}$ ), with a median of $148.0 \mathrm{~cm}$. The mean height of the seventy-five non-indigenous women was 151.9 (SD 5.6) cm, as compared with 146.5 (SD 5.0) cm among the 229 women of indigenous descent $(P<0 \cdot 001)$. Height measurements were missing for two women.

The overall prevalence of stunting of all infants less than 6 weeks of age was $33 \%$, with a median HAZ of -1.50 . We have illustrated in Fig. 1 the mean HAZ values of the rural-village site $(\boldsymbol{\Lambda})$ and the urban-clinic site $(\square)$ at 1 month. The reference curve above $(--)$ is the 12-month course of the composite HAZ values for the fiftyfour low- and middle-income nations from WHO-collected survey data and published by Victora et al. ${ }^{(16)}$. At 1 month, our HAZ values fall well below the level of the composite reference throughout the entire first year of life. In fact, it would not be until the 15 th to 17 th month of life (data not shown) that the reference HAZ curve would have reached the level of linear growth decline observed in the urban-clinic and rural-village Guatemalan infants, respectively, within a month of birth.

We show in Fig. 2 a scatter plot of age in days at measurement of length ( $x$-axis) $v$. HAZ ( $y$-axis), along with the linear regression line $\left(r^{2}=0 \cdot 010\right)$. Simple linear regression revealed no relationship between age of the infant and $\operatorname{HAZ}(\beta=-0 \cdot 101, t(304)=-1.777, P=0.077)$. Figure 3 illustrates the scatter plot of maternal height in centimetres ( $x$-axis) $v$. infant HAZ ( $y$-axis), and the linear regression line $\left(r^{2}=0.029\right)$. This simple linear regression revealed a significant positive relationship between maternal height and HAZ $(\beta=0.171, \quad t(302)=3 \cdot 023$, $P=0 \cdot 003)$, meaning that infants with taller mothers had higher HAZ. Maternal height explains $3 \%$ of the variability in infant HAZ $\left(r^{2}=0.029\right)$. Figure 4 provides a graphical representation of the partition among non-stunted, moderately stunted and severely stunted in the urban-clinic $v$. rural-village setting.

As shown in Table 1, there was an $11 \%$ lower median HAZ $(P=0 \cdot 167)$, and a $52 \%$ lower stunting prevalence within the first $45 \mathrm{~d}$ of life, in the urban-clinic group as

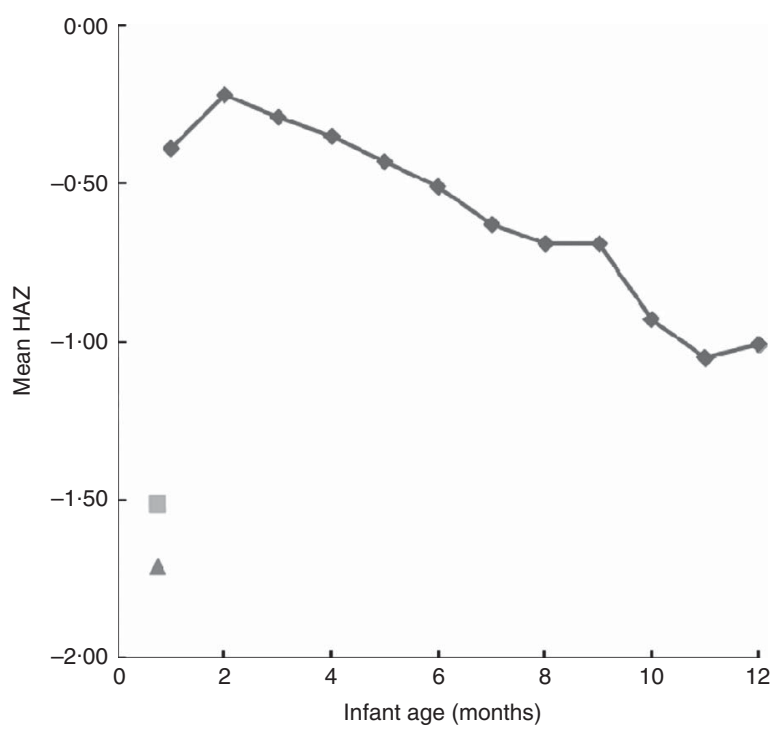

Fig. 1 Mean length-for-age Z-score (HAZ) within urban and rural study sites $v$. timing of growth faltering worldwide (compiled from fifty-four low- and middle-income countries) as followed from 1 month through the first year of life. The composite reference data $(-<)$ are re-plotted from the original data from reference Victora et al. ${ }^{(16)}$ as kindly provided by Professor Cesar Victora. The mean HAZ of the rural-village sample $(\Lambda)$ and the mean $H A Z$ of the urban-clinic sample ( $)$ were obtained from newborns with a median age of $19 \mathrm{~d}$ from eight rural villages ( $n 200)$ and an urban clinic $(n 106)$ in Quetzaltenango, western highlands of Guatemala

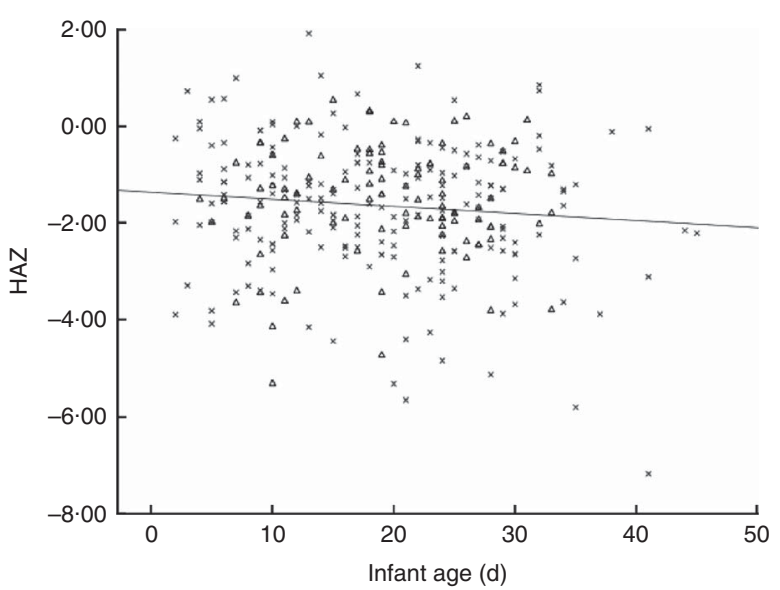

Fig. 2 Scatter plot of infant age in days ( $x$-axis) $v$. infant lengthfor-age $Z$-score (HAZ; $y$-axis) and regression line for combined rural-village and urban-clinic infants $(n$ 306, $r=0.101$, $\left.r^{2}=0.010, P=0.077\right)$. Data were obtained from newborns with a median age of $19 \mathrm{~d}$ from eight rural villages $(n 200 ; \times)$ and an urban clinic $(n 106 ; \Delta)$ in Quetzaltenango, western highlands of Guatemala

compared with the rural-village group, which reached significance $(P=0.034)$. Table 2 disaggregates rural-village and urban-clinic sub-samples by newborn sex. No difference between sexes was found at the rural-village site whereas at the urban-clinic site, the boys had a $38 \%$ lower 


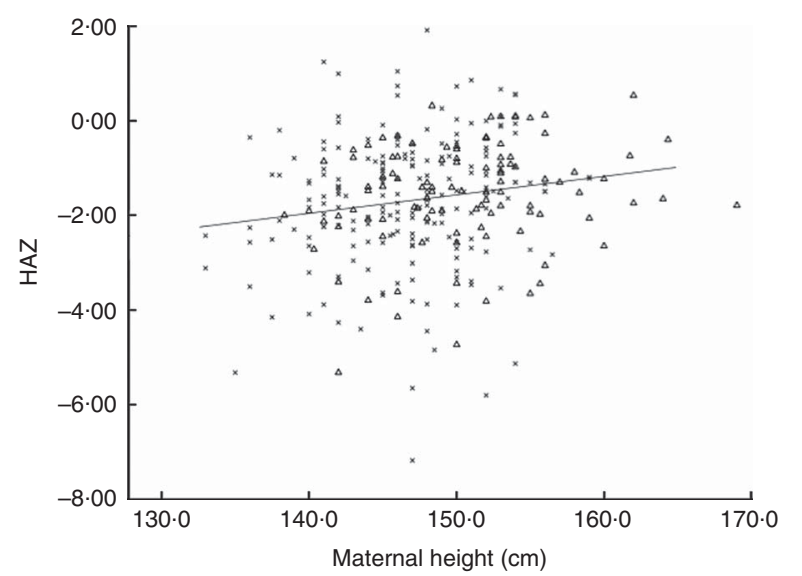

Fig. 3 Scatter plot of maternal height in centimetres ( $x$-axis) $v$. infant length-for-age $Z$-score (HAZ; $y$-axis) and regression for combined rural-village and urban-clinic mother-infant dyads ( $n$ 304, $r^{2}=0.029 . r=0.171, P=0.003$ ). Data were obtained from mothers and their newborns with a median age of $19 \mathrm{~d}$ from eight rural villages $(n 200 ; \times)$ and an urban clinic ( $n$ 106; $\Delta)$ in Quetzaltenango, western highlands of Guatemala (a)

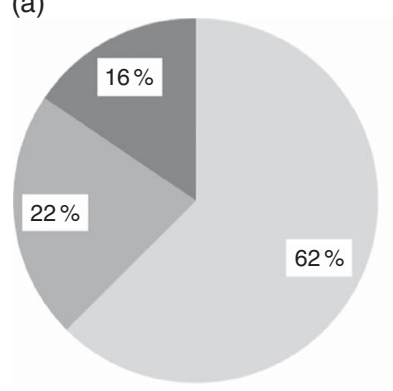

(b)

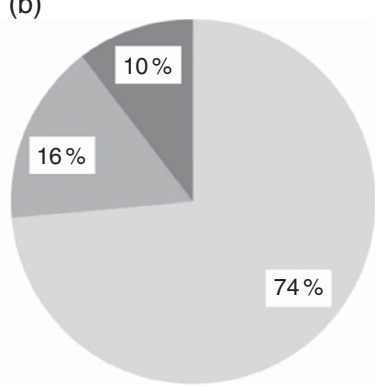

Fig. 4 Prevalence of infant stunting (, , adequate growth, length-for-age $Z$-score $(H A Z)<+2$ and $\geq-2$;, moderate stunting, $H A Z \geq-3$ and $<-2$; $\square$, severe stunting, $H A Z<-3$ ) in relation to the WHO reference median ${ }^{(4)}$ in (a) the ruralvillage and (b) the urban-clinic sample. Data were obtained from newborns with a median age of $19 \mathrm{~d}$ from eight rural villages ( $n 200)$ and an urban clinic ( $n 106)$ in Quetzaltenango, western highlands of Guatemala mean HAZ than the girls, which was statistically significant $(P=0 \cdot 040)$.

\section{Discussion}

The major observation of the present study is the unexpected rate of both moderate and severe stunting in babies less than 6 weeks of age. The high prevalence of stunting in pre-school children in Guatemala has been an increasingly important policy concern in the nation ${ }^{(23)}$. It has been linked with the epidemiological and biological paradigm of the 'window of opportunity' of the first $1000 \mathrm{~d}$ of life - from conception to the second birthday - which has become a guiding principle for programmatic action to prevent permanent deficits in growth and development ${ }^{(24,25)}$. Historically speaking, the insights for delineating this period came from observations derived from a longitudinal study in the eastern zone of Guatemala, begun in the $1960 \mathrm{~s}^{(26)}$, where only interventions reaching the mother-infant dyad prior to 24 months had measureable impacts on growth and development. Even within the current 1000 d framework, however, a keen realization of the in utero occurrence of linear growth faltering has not been incorporated into the programmatic mobilization.

A closer inspection of the disaggregation by sex and ethnicity is worthwhile. Based on nationally representative data from the most recent survey ${ }^{(27)}$ for the entire 6-24 months period, indigenous children in Guatemala have a $65.9 \%$ stunting prevalence as compared with a $36.2 \%$ prevalence for non-indigenous. Although there were no significant differences in the median HAZ between the rural-village series, entirely of indigenous descent, and the urban-clinic series, only $28 \%$ indigenous, there was a slight numerical inclination towards the rural; but no dramatic ethnic disparity was yet reflected within the first month of life.

What does stand out in Table 2, however, is the differential HAZ status between the sexes within the urban-clinic sample, with a significantly higher stunting prevalence

Table 1 Demographics and prevalence of infant stunting by study site ( $n$ 306). Data were obtained from newborns with a median age of $19 \mathrm{~d}$ from eight rural villages $(n 200)$ and an urban clinic $(n$ 106) in Quetzaltenango, western highlands of Guatemala

\begin{tabular}{|c|c|c|c|c|c|c|}
\hline & \multirow[b]{2}{*}{$n$} & \multicolumn{3}{|c|}{$H A Z^{*}$} & \multirow[b]{2}{*}{ Proportion of stuntingt (\%) } & \multirow[b]{2}{*}{ Proportion of severe stunting $\ddagger(\%)$} \\
\hline & & Median & Mean & SD & & \\
\hline Rural-village site & 200 & -1.56 & -1.71 & $1 \cdot 38$ & 38 & 16 \\
\hline Urban-clinic site & 106 & -1.41 & -1.51 & $1 \cdot 12$ & 25 & 10 \\
\hline$P$ value & & $0.167 \S$ & & & $0.034 \|$ & $0.215 \|$ \\
\hline
\end{tabular}

HAZ, length-for-age Z-score.

*Based on 2006 WHO growth standards ${ }^{(4)}$

†Stunting was defined as $\mathrm{HAZ}<-2.0$ in relation to the WHO reference median ${ }^{(4)}$.

$¥$ Severe stunting was defined as $\mathrm{HAZ}<-3.0$ in relation to the WHO reference median ${ }^{(4)}$.

$\S P$ value for the difference between study sites using the non-parametric Mann-Whiney $U$ test.

$\| P$ value for the difference between the study sites using the $X^{2}$ test. 
Table 2 Prevalence of infant stunting by sex and study site ( $n$ 306). Data were obtained from newborns with a median age of $19 \mathrm{~d}$ from eight rural villages ( $n$ 200) and an urban clinic $(n 106)$ in Quetzaltenango, western highlands of Guatemala

\begin{tabular}{|c|c|c|c|c|c|c|}
\hline & \multirow[b]{2}{*}{$n$} & \multirow{2}{*}{$\begin{array}{c}\text { Proportion indigenous } \\
(\%)\end{array}$} & \multicolumn{3}{|c|}{$H A Z^{*}$} & \multirow{2}{*}{$\begin{array}{c}\text { Proportion of stunting } \dagger \\
(\%)\end{array}$} \\
\hline & & & Median & Mean & SD & \\
\hline \multicolumn{7}{|c|}{ Rural-village site } \\
\hline Boys & $110(55 \%)$ & 100 & -1.57 & -1.76 & 1.46 & 37 \\
\hline $\begin{array}{l}\text { Girls } \\
P \text { value }\end{array}$ & $90(45 \%)$ & 100 & $\begin{array}{l}-1.49 \\
0.618 \ddagger\end{array}$ & -1.64 & $1 \cdot 28$ & $\begin{array}{c}38 \\
0.119 \S\end{array}$ \\
\hline \multicolumn{7}{|c|}{ Urban-clinic site } \\
\hline Boys & $53(50 \%)$ & 32 & -1.64 & -1.75 & 1.16 & 32 \\
\hline $\begin{array}{l}\text { Girls } \\
P \text { value }\end{array}$ & $53(50 \%)$ & 23 & -1.40 & $-1 \cdot 27$ & 1.02 & 19 \\
\hline
\end{tabular}

HAZ, length-for-age Z-score.

*Based on 2006 WHO growth standards ${ }^{(4)}$

†Stunting was defined as $\mathrm{HAZ}<-2.0$ in relation to the WHO reference median ${ }^{(4)}$

$\ddagger P$ value for the difference between sexes within study sites using the non-parametric Mann-Whiney $U$ test.

$\S P$ value for the difference between sexes within study sites using the $X^{2}$ test.

in boys. The greater nutritional vulnerability of males in a resource- or nutrient-constrained setting is not unheard of in epidemiology. Only male children increased weight gain in a Zn-supplementation study in Colorado ${ }^{(28)}$. Similarly, males were $32 \%$ more likely to have xerophthalmia than females in a survey on a South Pacific island ${ }^{(29)}$. Severe proteinenergy malnutrition has been reported to be more prevalent in males in some series ${ }^{(30,31)}$. Even modelling national availability of energy in the food supply, Williams and Gloster $^{(32)}$ found a negative influence on the male:female human sex ratio. The intrinsically programmed growth trajectory for male infants is greater than that for females ${ }^{(18)}$ with consequent higher demands for most nutrients. With constraints on access to or retention of nutrients, males would be expected to reach an imbalance tipping point earlier and more frequently than their female peers.

One can speculate that this 'missing the forest for the trees' phenomenon - the general lack of attention to birth length - might relate to the ingrained focus on birth weight as a variable of interest in clinical medicine and public health. This has a technical dimension. Whereas weight, on the one hand, is readily and routinely measured at birth, there is a certain reticence, on the other hand, to perform a rigorous length measurement at delivery. Due to fear of causing skeletal injury to the newborn in complete straightening of the body, along with scepticism about whether length can be measured consistently in routine data records, authorities and authors have widely disregarded birth length as a reliable variable and firmly focused their interest in early-life growth disorders of weight at birth. In the clinical and neonatology domain, small-for-gestationalage is the entity of interest for poor intra-uterine growth, defined exclusively in relation to standards of weight at birth $^{(33,34)}$. Likewise, in the epidemiological sphere, intrauterine growth retardation based on birth weight is the paradigm of public health interest ${ }^{(35,36)}$. Absolute weight in grams at birth and the 'underweight' classification by weight-for-age remain the dominant terms of reference in early infancy.
Several widely cited publications, however, may have left a general impression that retardation of linear growth does not become a problem of interest until later in infancy. A study cited to support exclusive-breast-feeding policy was performed among deprived families of greater Lima, Peru in the 1990s; the reported birth lengths of poor neonates were comparable to those of their comparison group from privileged conditions of Davis, California and linear growth was parallel through 9 months $^{(37)}$. In response to that publication, Rivera and Ruel ${ }^{(38)}$ in Guatemala mobilized data from a study from the 1960s to identify a subgroup of breast-fed infants whose length growth fell off as early as 3 months, but earlier measurements were not included. The impression given by the WHO-sponsored compendium by Victora et al. ${ }^{(16)}$, abstracted as the basis of our Fig. 1, may have a contemporary effect on normative thinking about length at birth. In fact, its first data point is at 1 month, but the mean HAZ by month 2 is close to $-0 \cdot 20$. The database for that curve is the combined national survey data from fifty-four low- and middle-income countries. The composite mean projects the impression of little aggregate length problem in the neonatal period. A quotation from a contribution from a Chinese and Swedish collaboration in 2000, 'Linear growth retardation (stunting) is prevalent (10-80\%) in developing countries. It takes place between 6 and 18 months of age...', may be typical of the widespread ignoring of an early-onset possibility for stunting ${ }^{(39)}$.

For reasons alluded to throughout the text, the dominant anthropometric focus at birth and in early infancy is on body weight, with length measurement relegated to a lower priority. Nevertheless, we have identified studies, both from Guatemala and in the international literature, with which to compare the present findings. Birth length is often part of protocols in long-term cohort studies bridging from birth through childhood and towards adulthood $^{(40-45)}$ or short-term, longitudinal observational studies seeking to find correlates of early growth or health ${ }^{(46-53)}$. More recently, length is measured at birth as part of studies evaluating inter-pregnancy interventions in 
the mother on outcomes of birth size and early growth ${ }^{(54-56)}$. The length determinations often come from community workers trained and equipped to perform anthropometry for the studies, and up to 48 to $72 \mathrm{~h}$ postpartum is often allowed as a margin for measurement. Schmidt et al. ${ }^{(52)}$ mimic our experience to the extent that only sixty-eight of the 312 infants enrolled within $30 \mathrm{~d}$ of birth were measured within $72 \mathrm{~h}$. In a report from Cebu in the Philippines among 2859 mothers with a mean height of $150.6 \mathrm{~cm}, 5 \%$ of infants were stunted at birth ${ }^{(40)}$. Among 170 term births to mothers in a Mexico City slum, the mean HAZ at birth was $-0 \cdot 80$, with no estimate of stunting frequency ${ }^{(53)}$. In general among these reports, however, little or nothing is remarked on the descriptive statistic of birth stunting prevalence.

Specifically with respect to Guatemala, anthropometric data from the legendary 1960s longitudinal nutritional intervention study in four villages in an eastern province were revisited a quarter of a century later; the title topics included 'growth retardation'(38) and 'length ... in stunted populations ${ }^{\text {,57) }}$. The former, however, refers to weightfor-age, and the authors' reticence to avail themselves of neonatal length measurements in the database is attested to by the fact that 3-month HAZ is the earliest datum used in both studies. In the new millennium, the actual villages were revisited to study the offspring of the original child participants. In this protocol, both ultrasonic monitoring of fetal growth and birth lengths were measured ${ }^{(58,59)}$. In another study, hospital record data from a rural hospital were used to differentiate intra-uterine growth retardation, based on low birth weight, into its chronic and acute varieties; this was accomplished with secondary measurements that included head circumference, abdominal circumference and length at birth ${ }^{(60)}$. Finally, working in a rural Mayan indigenous village of the central highlands of Guatemala, Berngard et al. ${ }^{(19)}$ documented a mean HAZ at an average of $5.7 \mathrm{~d}$ after birth from project-staff measurements of -1.0 (SD 1.0) among 148 newborns. Although the stunting prevalence was not reported, if the length distribution were normally distributed, this would correspond to about a $16 \%$ rate.

We cannot exclude a heritable genetic component for the slower intra-uterine linear growth, although it is a near consensus in biological anthropology that the growth potential for most racial groups is common ${ }^{(61)}$. An environmental cause would centre on poor dietary practices of the mother, impaired nutrient delivery to the placenta or both, as well as the environmental assaults on the mother. In the interior provinces of Guatemala, factors such as poor prenatal care, recurrent infection and even exposure to indoor wood-fire smoke ${ }^{(62)}$ would be candidates. To the extent that these environmental factors produce oxidative and inflammatory stress, hormonal mechanisms for disrupting elongation of bones in utero are now well described in animal models ${ }^{(63,64)}$. Although dietary and environmental conditions certainly differ between the urban and rural study settings of our series, we found no significant inter-setting difference in stunting rates or HAZ.

The short maternal stature of the mothers is of concern. A high prevalence of adult stunting was documented in a survey of all mothers measured in the urban-clinic series $^{(65)}$. The mean height of the 542 mothers in that study was $149 \cdot 2$ (SD 5.9 ) cm, with $59 \%$ standing less than $150 \cdot 3 \mathrm{~cm}$ tall (data not shown). As pelvic dimensions are directly associated with maternal height ${ }^{(2)}$, stunted mothers are at risk of obstetric complications during the delivery of infants even of the median size of the international standards ${ }^{(4)}$. It would somehow be fortuitous, therefore, if there existed a mechanism that adjusted the baby's birth size to the pelvic capacity. Against the operation of such an adaptation, however, is the finding that, in the current sample, maternal height explains only $3 \%$ of the variance in HAZ in our regression $\left(r^{2}=0.029\right)$. Given the short stature, however, it is logical that any push for Guatemala newborns to achieve international standard birth size must be guided with moderation until the pelvic capacities are of more ample proportions in women of the western highlands.

The present study has certain acknowledged strengths and weaknesses. It is more an opportunity-based compilation of findings from two studies than a prospectively designed inquiry. In fact, the assumptions of both studies were that the linear growth trajectories would approximate those graphed in the international reviews ${ }^{(16,66)}$. No sample-size calculation for considerations of stability of prevalence estimates was built into the design of either study and the urban-clinic project involved recruitment of a convenience sample, not necessarily representative of the setting's overall population. Both studies, however, shared the same measuring equipment and training and standardization, and enrolled infants between 2 and $45 \mathrm{~d}$ of life. Within this interval, safer and more deliberate extension of the infant's body for supine measure can be made than on the day of delivery, either in the midwifery or maternity hospital setting. Our use of the headline term of 'stunting at birth', moreover, seems justifiable, since little movement among growth channels would be expected within this short postpartum interval, as confirmed in Fig. 2. Recruitment in a health clinic could introduce an unknown degree of bias for infants aged 4 to $33 \mathrm{~d}$; they were attending the facility this early in life for a number of well-baby and maternal concerns. As such, the early enrollees could represent a subgroup of children with health or nutritional concerns in early life, distinct from their recently born age peers across the low-income community as a whole. In our view, any exclusion of infants based on gestational age actually reduces the accounting of net low length at birth. We must admit, however, that the disparate criteria for inclusion or exclusion by gestational age make comparisons across our two Guatemalan sites, and with the publication from the centre of the nation ${ }^{(19)}$, less precise. This heterogeneity, 
moreover, may have been a factor in the time-dependent association illustrated in Fig. 2. Finally, therefore, while perhaps not providing the definitive incidences of stunting in the recently born infant for either the urban-clinic or the rural-village sector of Quetzaltenango Province, a substantial and disconcerting number of individuals have full linear growth retardation of intra-uterine origin.

Accepting, then, that rates of stunting - and a general leftward shift of HAZ distributions - are present in certain neonates in the interior of Guatemala here and elsewhere $^{(19)}$ adds a new dimension to established policy considerations. The demonstrable existence of stunting-atbirth might serve to redirect and reorient the strategies and policies surrounding the first $1000 \mathrm{~d}$ policy. It undoubtedly highlights the importance of a focus on the mother, and the female lineage, in bolder relief. If the goal is to moderate stunting rates, it is essential to prevent the condition, as efforts for reversal of established short stature have so far proved unsatisfactory in general ${ }^{(67,68)}$. The key focus is the mother. Logic dictates, moreover, that it will take an intergenerational effort and course to safely bring a resolution to the Guatemalan public health problem of short stature ${ }^{(69)}$. Thus, we associate ourselves with the conclusions of Berngard et al. ${ }^{(19)}$ on similar observations in Guatemala: 'The primary conclusion is that impaired foetal linear growth is the major predictor of early infant linear growth failure indicating that prevention needs to start with maternal interventions'. This likely begins by mobilizing more than cursory attention to the nutritional needs, infection control and environmental-stress reduction interventions for low-income women both prior to and after conception that is focusing on the maternal determinants of supporting fetal growth. As the female offspring achieves lower stunting-at-birth rates and we gain better prevention of additional postpartum growth retardation, the adult heights and corresponding pelvic capacity of the next generation(s) of highland mothers will support safe deliveries of ever larger and longer newborns; this should result in an upward spiral unravelling the quandary of stunting - in both urban-clinic and rural-village settings for the most affected nation in the western hemisphere. Additional data collected on length of young infants in other parts of Guatemala as well as other resource-poor settings would enable us to generalize the findings obtained from the western highlands, which would broaden global health policy recommendations.

\section{Acknowledgements}

Acknowledgements: The authors thank the nutritionists who performed anthropometric measurements and interviewed the urban mothers (Elena María Díaz Ruiz, Claudia Alejandra Maldonado, Marta Escobar and Deborah Fuentes); Maria Garcia Maldonado and the students who helped recruit participants and enter data; the staff of the Quetzaltenango health centre; and the staff in the rural Mam-Mayan communities. Mostly they thank the participants of the study for their collaboration. Financial support: Financial support was obtained from the 'Nestle Foundation for the Study of Problems of Nutrition in the World', Switzerland; the 'SDEGraduate Women in Science', USA; the 'Global Health Research Capacity Strengthening Program', Canada; the 'Programme de Bourses d'Excellence pour Etudiants Etrangers (PBEEE)', Quebec, Canada; the 'McGill University Graduate Travel Award'; and the Institute of Parasitology at McGill University Graduate 'Excellence Fellowship'. Research at the Institute of Parasitology is supported by a 'Regroupement stratégique' grant from 'Fonds de recherche du Québec - Nature et technologies'. The funders had no role in the design, analysis or writing of this article. Conflict of interest: None. Authorship: N.W.S. participated in the conception and design of the study, interpretation of data, drafting of the manuscript, obtaining funding and supervision. M.V. participated in the conception and design of the study, analysis and interpretation of data, drafting of the manuscript, obtaining funding and supervision. A.-M.C. participated in the conception and design of the study, data collection, analysis and interpretation of data, drafting of the manuscript, obtaining funding and supervision. C.M.D., K.G.K. and M.E.S. participated in the conception and design of the study, interpretation of data, supervision and critical revision of the manuscript. Ethics of human subject participation: Ethics approval was obtained from McGill University (rural study) and from CeSSIAM (urban and rural studies).

\section{References}

1. Dewey KG \& Begum K (2011) Long-term consequences of stunting in early life. Matern Child Nutr 7, Suppl. 3, $5-18$.

2. Toh-Adam R, Srisupundit K \& Tongsong T (2012) Short stature as an independent risk factor for cephalopelvic disproportion in a country of relatively small-sized mothers. Arch Gynecol Obstet 285, 1513-1516.

3. UNICEF (2009) State of the World's Children: Tracking progress on child and maternal nutrition - a survival and development priority. http://www.unicef.pt/docs/Progress_ on_Child_and_Maternal_Nutrition_EN_110309.pdf (accessed May 2013).

4. World Health Organization (2006) WHO Child Growth Standards: Length/Height-for-Age, Weight-for-Age, Weightfor-Length, Weight-for-Height and Body Mass Index-for Age: Methods and Development. Geneva: WHO.

5. Solomons NW, Mazariegos M, Brown KH et al. (1993) The underprivileged, developing country child: environmental contamination and growth failure revisited. Nutr Rev $\mathbf{5 1}$, 327-332.

6. Khlangwiset P, Shephard GS \& Wu F (2011) Aflatoxins and growth impairment: a review. Crit Rev Toxicol 41, 740-755.

7. Smith LE, Stoltzfus RJ \& Prendergast A (2012) Food chain mycotoxin exposure, gut health, and impaired growth: a conceptual framework. Adv Nutr 3, 526-531.

8. Ghosh R, Amirian E, Dostal M et al. (2011) Indoor coal use and early childhood growth. Arch Pediatr Adolesc Med $\mathbf{1 6 5}$, 492-497. 
9. Martorell R, Habicht JP, Yarbrough C et al. (1975) Acute morbidity and physical growth in rural Guatemalan children. Am J Dis Child 129, 1296-1301.

10. Guerrant RL, DeBoer MD, Moore SR et al. (2013) The impoverished gut - a triple burden of diarrhoea, stunting and chronic disease. Nat Rev Gastroenterol Hepatol 10, 220-229.

11. Bustinduy AL, Parraga IM, Thomas CL et al. (2013) Impact of polyparasitic infections on anemia and undernutrition among Kenyan children living in a Schistosoma haematobiumendemic area. Am J Trop Med Hyg 88, 433-440.

12. Ulukanligil M \& Seyrek A (2004) Anthropometric status, anaemia and intestinal helminthic infections in shantytown and apartment schoolchildren in the Sanliurfa province of Turkey. Eur J Clin Nutr 58, 1056-1061.

13. DeBoer MD, Lima AA, Oria RB et al. (2012) Early childhood growth failure and the developmental origins of adult disease: do enteric infections and malnutrition increase risk for the metabolic syndrome? Nutr Rev 70, 642-653.

14. Keusch GT, Rosenberg IH, Denno DM et al. (2013) Implications of acquired environmental enteric dysfunction for growth and stunting in infants and children living in lowand middle-income countries. Food Nutr Bull 34, 357-364.

15. Ngure FM, Reid BM, Humphrey JH et al. (2014) Water, sanitation, and hygiene (WASH), environmental enteropathy, nutrition, and early child development: making the links. Ann N Y Acad Sci 1308, 118-128.

16. Victora CG, de Onis M, Hallal PC et al. (2010) Worldwide timing of growth faltering: revisiting implications for interventions. Pediatrics 125, e473-e480.

17. Borghi E, de Onis M, Garza C et al. (2006) Construction of the World Health Organization child growth standards: selection of methods for attained growth curves. Stat Med 25, 247-265.

18. WHO Multicentre Growth Reference Study Group (2006) Enrolment and baseline characteristics in the WHO Multicentre Growth Reference Study. Acta Paediatr Suppl 450, 7-15.

19. Berngard SC, Berngard JB, Krebs NF et al. (2013) Newborn length predicts early infant linear growth retardation and disproportionately high weight gain in a low-income population. Early Hum Dev 89, 967-972.

20. Reurings M, Vossenaar M, Doak CM et al. (2013) Stunting rates in infants and toddlers born in metropolitan Quetzaltenango, Guatemala. Nutrition 29, 655-660.

21. van Beusekom I, Vossenaar M, Montenegro-Bethancourt G et al. (2013) Estimates of exclusive breastfeeding rates among mother-infant dyads in Quetzaltenango, Guatemala, vary according to interview method and time frame. Food Nutr Bull 34, 160-168.

22. Lohman T, Roche AF \& Martorell R (1988) Anthropometric Standardization Reference Manual. Campaign, IL: Human Kinetics Books.

23. Secretaria de Seguridad Alimentaria y Nutricional, Gobierno de Guatamala (2012) Plan for the zero hunger pact for Guatemala (El plan del pacto hambre cero, Guatemala). http://issuu.com/sesansecretaria/docs/pacto_hambre_cero/ 19 ? $=5172177 / 1152849$ (accessed June 2013).

24. 1000 Days Partnership (2011) 1,000 days: Change a life, change the future. http://www.thousanddays.org/about/ (accessed June 2013).

25. UNICEF (2013) UNICEF Report: Critical importance of first 1,000 days of life. http://www.pncius.org/update.aspx? $\mathrm{id}=79$ (accessed June 2013).

26. Habicht JP \& Martorell R (2010) Probability, plausibility, and adequacy evaluations of the Oriente Study demonstrate that supplementation improved child growth. J Nutr 140, 407-410.

27. Instituto Nacional de Estadistica (2009) V Encuesta Nacional de Salud Materno Infantil (ENSMI) 2008-2009. Guatemala: Instituto Nacional de Estadistica.
28. Walravens PA, Hambidge KM \& Koepfer DM (1989) Zinc supplementation in infants with a nutritional pattern of failure to thrive: a double-blind, controlled study. Pediatrics 83, 532-538.

29. Schaumberg DA, O'Connor J \& Semba RD (1996) Risk factors for xerophthalmia in the Republic of Kiribati. Eur J Clin Nutr 50, 761-764.

30. Bachou H, Tylleskar T, Downing R et al. (2006) Severe malnutrition with and without HIV-1 infection in hospitalised children in Kampala, Uganda: differences in clinical features, haematological findings and CD $4+$ cell counts. Nutr J 5, 27.

31. Alvear J, Artaza C, Vial M et al. (1986) Physical growth and bone age of survivors of protein energy malnutrition. Arch Dis Child 61, 257-262.

32. Williams RJ \& Gloster SP (1992) Human sex ratio as it relates to caloric availability. Soc Biol 39, 285-291.

33. Cetin I, Marconi AM, Bozzetti P et al. (1988) Umbilical amino acid concentrations in appropriate and small for gestational age infants: a biochemical difference present in utero. Am J Obstet Gynecol 158, 120-126.

34. Tudehope D, Vento M, Bhutta Z et al. (2013) Nutritional requirements and feeding recommendations for small for gestational age infants. J Pediatr 162, 3 Suppl., S81-S89.

35. Villar J \& Belizan JM (1982) The relative contribution of prematurity and fetal growth retardation to low birth weight in developing and developed societies. Am J Obstet Gynecol 143, 793-798.

36. Villar J \& Belizan JM (1986) The evaluation of the methods used in the diagnosis of intrauterine growth retardation. Obstet Gynecol Surv 41, 187-199.

37. Dewey KG, Peerson JM, Heinig MJ et al. (1992) Growth patterns of breast-fed infants in affluent (United States) and poor (Peru) communities: implications for timing of complementary feeding. Am J Clin Nutr 56, 1012-1018.

38. Rivera J \& Ruel MT (1997) Growth retardation starts in the first three months of life among rural Guatemalan children. Eur J Clin Nutr 51, 92-96.

39. Liu Y, Albertsson-Wikland K \& Karlberg J (2000) Long-term consequences of early linear growth retardation (stunting) in Swedish children. Pediatr Res 47, 475-480.

40. Adair LS \& Guilkey DK (1997) Age-specific determinants of stunting in Filipino children. J Nutr 127, 314-320.

41. Karlberg J, Ashraf RN, Saleemi M et al. (1993) Early child health in Lahore, Pakistan: XI. Growth. Acta Paediatr Suppl 82, Suppl. 390, 119-149.

42. Mostert D, Steyn NP, Temple NJ et al. (2005) Dietary intake of pregnant women and their infants in a poor black South African community. Curationis 28, 12-19.

43. Mamabolo RL, Alberts M, Steyn NP et al. (2005) Prevalence and determinants of stunting and overweight in 3-year-old black South African children residing in the Central Region of Limpopo Province, South Africa. Public Health Nutr 8 , 501-508.

44. Saha KK, Frongillo EA, Alam DS et al. (2009) Household food security is associated with growth of infants and young children in rural Bangladesh. Public Health Nutr 12, $1556-1562$.

45. Sterling R, Miranda JJ, Gilman RH et al. (2012) Early anthropometric indices predict short stature and overweight status in a cohort of Peruvians in early adolescence. $A m J$ Phys Anthropol 148, 451-461.

46. Hovhannisyan L, Demirchyan A \& Petrosyan V (2014) Estimated prevalence and predictors of undernutrition among children aged 5-17 months in Yerevan, Armenia. Public Health Nutr 17, 1046-1053.

47. Kalanda BF, van Buuren S, Verhoeff FH et al. (2005) Catch-up growth in Malawian babies, a longitudinal study of normal and low birthweight babies born in a malarious endemic area. Early Hum Dev 81, 841-850. 
48. Khan AI, Kabir I, Ekstrom EC et al. (2011) Effects of prenatal food and micronutrient supplementation on child growth from birth to 54 months of age: a randomized trial in Bangladesh. Nutr J 10, 134.

49. Lopez deRomana G, Brown KH, Black RE et al. (1989) Longitudinal studies of infectious diseases and physical growth of infants in Huascar, an underprivileged peri-urban community in Lima, Peru. Am J Epidemiol 129, 769-784.

50. Olusanya BO, Wirz SL \& Renner JK (2010) Prevalence, pattern and risk factors for undernutrition in early infancy using the WHO Multicentre Growth Reference: a communitybased study. Paediatr Perinat Epidemiol 24, 572-583.

51. Peterson KM, Buss J, Easley R et al. (2013) REG1B as a predictor of childhood stunting in Bangladesh and Peru. Am J Clin Nutr 97, 1129-1133.

52. Schmidt MK, Muslimatun S, West CE et al. (2002) Nutritional status and linear growth of Indonesian infants in West Java are determined more by prenatal environment than by postnatal factors. J Nutr 132, 2202-2207.

53. Villalpando S \& Lopez-Alarcon M (2000) Growth faltering is prevented by breast-feeding in underprivileged infants from Mexico City. J Nutr 130, 546-552.

54. Luntamo M, Kulmala T, Cheung YB et al. (2013) The effect of antenatal monthly sulphadoxine-pyrimethamine, alone or with azithromycin, on foetal and neonatal growth faltering in Malawi: a randomised controlled trial. Trop Med Int Health 18, 386-397.

55. Roth DE, Perumal N, Al Mahmud A et al. (2013) Maternal vitamin $\mathrm{D}_{3}$ supplementation during the third trimester of pregnancy: effects on infant growth in a longitudinal followup study in Bangladesh. J Pediatr 163, 1605-1611.e3.

56. Wang W, Yan H, Zeng L et al. (2012) No effect of maternal micronutrient supplementation on early childhood growth in rural western China: 30 month follow-up evaluation of a double blind, cluster randomized controlled trial. Eur J Clin Nutr 66, 261-268.

57. Ruel MT, Rivera J \& Habicht JP (1995) Length screens better than weight in stunted populations. J Nutr 125, 1222-1228.

58. Neufeld LM, Haas JD, Grajeda R et al. (2004) Changes in maternal weight from the first to second trimester of pregnancy are associated with fetal growth and infant length at birth. Am J Clin Nutr 79, 646-652.

59. Stein AD, Barnhart HX, Hickey M et al. (2003) Prospective study of protein-energy supplementation early in life and of growth in the subsequent generation in Guatemala. Am J Clin Nutr 78, 162-167.

60. Neel NR \& Alvarez JO (1991) Maternal risk factors for low birth weight and intrauterine growth retardation in a Guatemalan population. Bull Pan Am Health Organ 25, 152-165.

61. Frisancho AR (1993) Human Adaptation: A Functional Interpretation. Ann Arbor, MI: University of Michigan Press.

62. Thompson LM, Bruce N, Eskenazi B et al. (2011) Impact of reduced maternal exposures to wood smoke from an introduced chimney stove on newborn birth weight in rural Guatemala. Environ Health Perspect 119, 1489-1494.

63. Odiere MR, Koski KG, Weiler HA et al. (2010) Concurrent nematode infection and pregnancy induce physiological responses that impair linear growth in the murine foetus. Parasitology 137, 991-1002.

64. Odiere MR, Scott ME, Weiler HA et al. (2010) Protein deficiency and nematode infection during pregnancy and lactation reduce maternal bone mineralization and neonatal linear growth in mice. J Nutr 140, 1638-1645.

65. Oyesiku L, Solomons NW, Doak CM et al. (2013) Highland Guatemalan women are extremely short of stature, and no lactation duration effects on body composition are observed in a cross-sectional survey. Nutr Res 33, 87-94.

66. Shrimpton R, Victora CG, de Onis M et al. (2001) Worldwide timing of growth faltering: implications for nutritional interventions. Pediatrics 107, E75.

67. Golden MH (1994) Is complete catch-up possible for stunted malnourished children? Eur J Clin Nutr 48, Suppl. 1, S58-S70.

68. Martorell R, Khan LK \& Schroeder DG (1994) Reversibility of stunting: epidemiological findings in children from developing countries. Eur J Clin Nutr 48, Suppl. 1, S45-S57.

69. Martorell R \& Zongrone A (2012) Intergenerational influences on child growth and undernutrition. Paediatr Perinat Epidemiol 26, Suppl. 1, 302-314. 